\title{
Interfaces multisensoriais: espacialidades híbridas do corpoespaço*
}

\begin{abstract}
RESUMO
O texto aborda o contexto de interfaces multisensoriais para pensar a relação humano/máquina e suas formas específicas de operar. Ao assumir a fisicalidade corpórea dos usuários e a materialidade de objetos e do espaço como dados de entrada, questiona-se a possibilidade de reconfiguração do corpo na sua própria apresentação e percepção a partir das interações mediadas neste contexto. Essa condição híbrida e processual aponta modos específicos de apreensão e de comunicação, que interessam discutir neste trabalho. Após as abordagens teóricas sobre interfaces tangíveis e enactives, alguns trabalhos artísticos serão apresentados, diante das específicas propostas de construção e experimentação de estados sensórios. Assim, as propostas artísticas potencializam o corpo e o espaço nas suas condições matéricas, na medida em que a percepção dos mesmos articula elementos interdependentes para a construção sensível da realidade como uma experiência fenomenológica.
\end{abstract}

\section{PALAVRAS-CHAVE}

interfaces multisensoriais

relação humano/máquina

tecnologia móvel

\section{ABSTRACT}

The text is concerned with the multisensory interfaces used to think about the human/machine relationship and its specific ways to work. By getting the corporeal physicality of users and the materiality of the objects and the space as input data, it is necessary to investigate the possibility of bodily reconfiguration in its own presentation and perception through mediated interactions. The hybrid process has pointed out specific ways of apprehension and communication. After some theoretical thoughts about tangible and enactive interfaces, some artistic works will be presented because of their experimental proposals of sensory states. The artistic proposals have potentialized the body and space since they have articulated the sensitive construction of the reality as a phenomenological experience.

\section{KEY WORDS}

multisensory interfaces

human/machine relation

mobile technologyhybrid

\section{Luisa Paraguai \\ Professora da Universidade de Sorocaba/ UNISO/SC/ Brasil luisa.paraguai@prof.uniso.br}

Os dispositivos móveis, vestíveis ou não, vêm promovendo uma mediação humano/máquina peculiar aos usuários, marcadamente em suas atividades diárias, de forma que a gestualidade e/ou contato físico dos mesmos com as interfaces transformam-se literalmente em informação para os sistemas computacionais. Assim, o que parece diferenciá-los de outros dispositivos, não apenas como sistemas de representação, é a forma determinante com que o corpo em movimento do usuário são atuantes e constituem-se enquanto dados de entrada e de saída. Os usuários apresentam-se reconfigurados na sua gestualidade e terminam por construir uma compreensão corpórea e espacial peculiares, dinâmicas, que se estendem e contraem, diante da movimentação dos mesmos. A possibilidade de (re)configuração da espacialidade corpórea ao negociarem outros limites para a percepção tem evocado questões e apresenta-se como tema para reflexão neste texto. Admite-se então, a configuração de um corpo híbrido, onde o caráter natural mais recentemente remodelado pelas tecnologias móveis demanda um reposicionamento e outro entendimento diante das novas conexões entre o contexto físico - local e remoto, e o ciberespaço.

O texto aborda os dispositivos tecnológicos como interfaces multisensoriais na medida em que suas específicas interconexões promovem interferências na percepção dos usuários tanto pela visualidade (forma) como nas articulações dimensionais do espaço (comunicação); reforça-se o entendimento de um corpo agente e determinante na relação humano/máquina. O processo do fazer, entre o pensamento e a ação, contém o corpo como elemento articulador e organizador e essa condição processual, bem como a dinâmica baseada na circularidade entre a ação do usuário sobre aquilo que ele constituiu como objeto e, reflexivamente, a ação desse objeto sobre o mesmo, parecem apontar um modo específico de operar e estabelecer relações entre usuário/interface. Como afirma Moles (apud Santos, 1999, p.77) “os objetos são duplamente mediadores, porque se colocam entre o homem e a sociedade e entre o homem e sua situação material". A construção de conhecimento apresenta-se assim, dependente da condição de existência no mundo, e portanto, intrinsecamente relacionada com o entendimento de corpo, com a linguagem e com a história política e social de cada indivíduo.

\section{Corpo em ação: espaço em construção}

No contexto das interfaces tecnológicas recentes, cada vez mais a ação e percepção dos usuários imbricam-se em formas complexas que traçam dependências e interferências dependentes do meio onde acontecem. Isto vale 
dizer que das relações estabelecidas por um fluxo dinâmico de informações e trocas emergem espacialidades presentes, articuladas entre o físico e o virtual, ambas reais. O corpo, ao articular infinitas apropriações estéticas e vivenciais com os seus desdobramentos e experimentações expande os limites territoriais físicos e manifesta um acontecimento subjetivo. Para contextualizar estas articulações, apresenta-se inicialmente a interface dita tangível, procurando apontar a relação multimodal e situada no corpo para, em seguida, formular as relações da interface enactive, objetivo central deste texto.

\subsection{Interface tangível}

Muitas pesquisas recentes têm procurado embarcar sistemas computacionais e desenvolvido a relação usuário/computador mediada por objetos e ambientes do mundo físico. As interfaces tangíveis (Graspable user interfaces - GUT), diferentemente das gráficas, não trazem nenhuma distinção entre os dispositivos de entrada e os de saída de dados, uma vez que, os dispositivos de controle físico e de representação integram os mesmos elementos na maioria destas interfaces. Assim, enquanto as interfaces gráficas trabalham quase que exclusivamente com a representação icônica de ações, as tangíveis incorporam fisicamente as mesmas operações. (Ullmer e Ishii, 2000, p.915) Conclui-se que a relação entre representação e controle pontua objetivamente as diferenças entre as interfaces e determina as relações usuário/interface.

Assumem-se neste texto as interfaces tangíveis como sistemas híbridos, o que é reafirmado por Ullmer e Ishii (ibidem, p.917-919) quando apontam como característica principal destes artefatos a articulação de representações com o controle de informação em um processo de manipulação direta. Dispositivos de entrada e saída terminam em imbricações técnicas e processuais, compondo de maneira sistêmica características matéricas e funcionais. Para estes autores podem-se elencar quatro características, consideradas fundamentais para a formalização material dos dispositivos, e determinantes da relação entre representação e controle: as representações físicas são computacionalmente acopladas com informação digital, as representações físicas incorporam mecanismos para controle interativo, as representações físicas são sensorialmente imbricadas com representações digitais mediadas (ampliação visual via projeção, som), e o estado físico dos elementos tangíveis incorpora aspectos chave do estado digital do sistema. Assim, as interfaces tangíveis baseiam-se na composição entre representações física e digital, necessárias para mediar as informações dinâmicas, que não necessariamente ocorram apenas no ambiente físico ou no virtual respectivamente, mas contenham ações e interferências em ambos.

Fitzmaurice (1996) afirma que uma interface tangível diante de seus arranjos físicos e espaciais condiciona e potencializa um espaço de controle qualificado como "space-multiplexed", quando diferentes dispositivos po- dem ser designados para diferentes funções e estarem independentemente acessíveis. Este arranjo amplia a capacidade, aumentando a funcionalidade e reduzindo a complexidade da composição em função da forma, tamanho e posição dos controles físicos, ao mesmo tempo em que constrange outras escolhas diante das próprias leis do mundo físico, reconhecendo assim os limites da fisiologia humana e da morfologia do espaço físico.

Ao usar objetos físicos não apenas permite-se aos usuários empregar uma gama expressiva maior de gestualidades e ações, mas, também, recuperam-se habilidades e conhecimentos já adquiridos e incorporados na forma de manipulação dos mesmos. O cotidiano de todo indivíduo está repleto de objetos, cujas funções, texturas e formas, determinam maneiras específicas de pegar, carregar, acionar, jogar, e constroem assim práticas que passam a ser recuperadas em outras situações de ressignificação. As relações entre operação e função, assim recuperadas, apontam para o estudo da interface enacti$v e$, a ser desenvolvido no item a seguir.

\subsection{Interface enactive}

O termo "enaction" foi introduzido pela primeira vez por Jerome Bruner, na Psicologia Cognitiva, (Pasquinelli, 2007, p.93), quando afirmou que o conhecimento "enacti$v e^{\prime \prime}$ é construído a partir de competências que requisitam habilidades motoras durante o processo do fazer, como por exemplo dançar, tocar um instrumento musical, manipular objetos, andar de bicicleta. Diferentemente do conhecimento elaborado de forma icônica ou metafórica, este paradigma da cognição está centrado em dinâmicas sensório-motoras, atividades corpóreas, e coloca as mediações entre o indivíduo e seu ambiente como fundamentais e determinantes para a produção de significados; este conhecimento apresenta-se assim constituído por padrões de experiência incorporada, que necessariamente precisam ser cultural e socialmente compartilhados. A ação é considerada como pré-requisito para percepção; assim, os inputs sensórios, como o reconhecimento do entorno, apenas passam a significar na medida em que ações são realizadas. Como afirma Stewart (2007, p.90) "sem ação não existe mundo e nem percepção".

Para validar esta afirmação recuperam-se os trabalhos de vários artistas, Lygia Clark, Hélio Oiticica, Robert Morris e Richard Serra, que em diferentes momentos da história e com distintas tecnologias procuraram validar a construção da relação corpo-espaço no campo do poético. Lygia Clark com a experiência sensória do corpo no trabalho Nostalgia do corpo - corpo coletivo (figura 1) apresenta os corpos totalmente envolvidos na fronteira do vestir e de certa forma aprisionados pelo limite físico; a condição apresentada constrói a relação corpo/ espaço ao estimular uma ação e percepção diferenciadas diante do acontecimento. Hoje, com as tecnologias móveis reelabora-se a percepção do corpo, que se apresenta constantemente detectado e monitorado na sua 
ação e deslocamento espacial. As chamadas via celular e as trocas de arquivo via bluetooth rastreiam o usuário no ambiente físico e requisitam sua atenção, momentaneamente alterada para uma condição multitarefa.

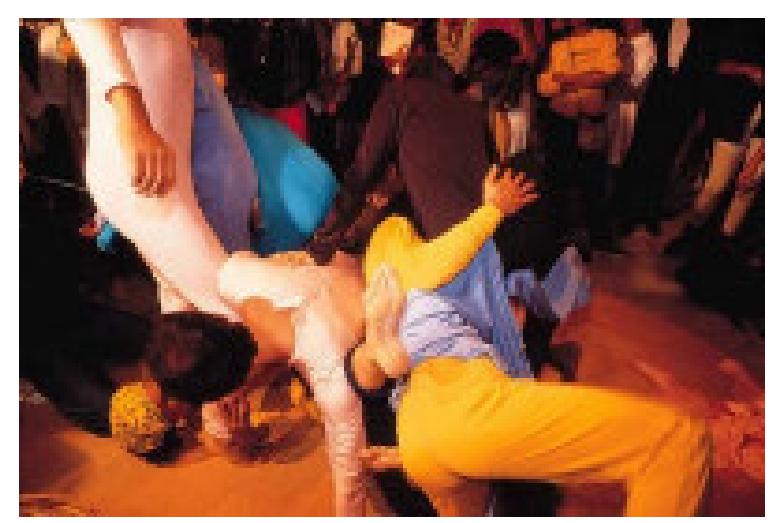

Figura 1: Nostalgia do corpo-corpo coletivo, Lygia Clark, 1965-88. Fonte: http://www.sbi.org.br/sbinarede/SBInarede63/ LygiaClarkNostalgiadoCorpoaCorpo1986.jpg

Hélio Oiticica com seus parangolés (figura 2) propõe uma aproximação estética com o cotidiano onde o corpo apresenta-se como um receptáculo de informações que se expande no comportamento e na aparência que transita no espaço. Nesta vivência do corpo-e-o-vestir, o espaço concreto articula com o espaço sensório e revela sentidos. A ação/movimento proporcionada pelo parangolé é extraída da visceralidade do corpo, da sua realidade concreta, da compreensão da arte/vida que ultrapassa o território de ocupação. A expansão sem limites do mundo íntimo do corpo está no cotidiano da conectividade.

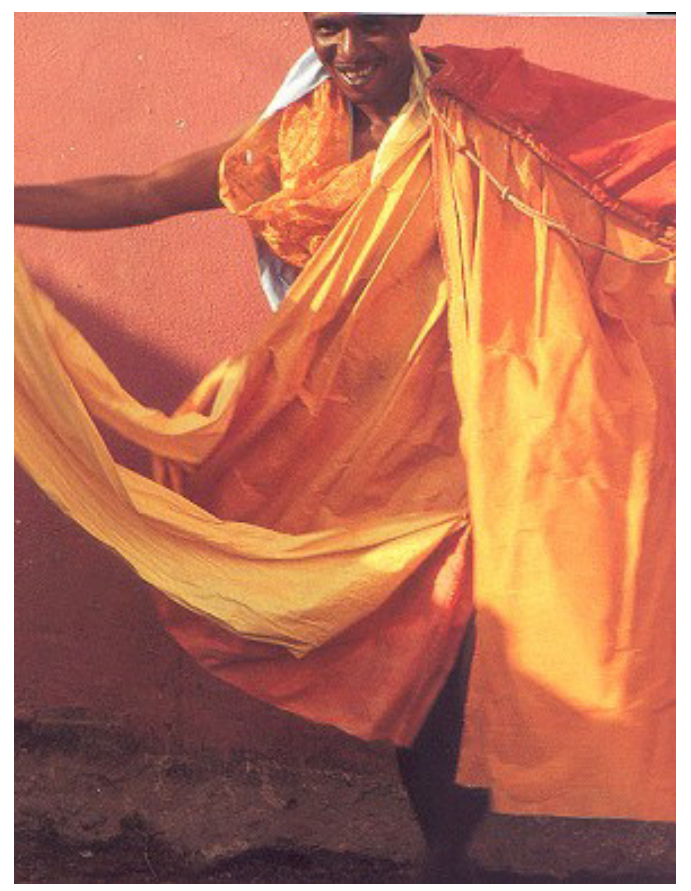

Figura 2: Nildo da Mangueira com Parangolé, Hélio Oiticica, 1964. Fonte: http://www.digestivocultural.com/ upload/jardeldiascavalcanti/parangole1.jpg.

O artista Robert Morris em seu trabalho untitled (figura 3) impõe ao visitante uma relação de encontro e definição do espaço, ora determinado pela construção de diferentes ângulos e pontos de vista, ora determinado pela inclusão visual da sua própria existência. A obra em si espelha o infinito pela regra simples de reflexão da física, mas com a presença dos visitantes, corpos em movimento, vê-se o espaço emergir.

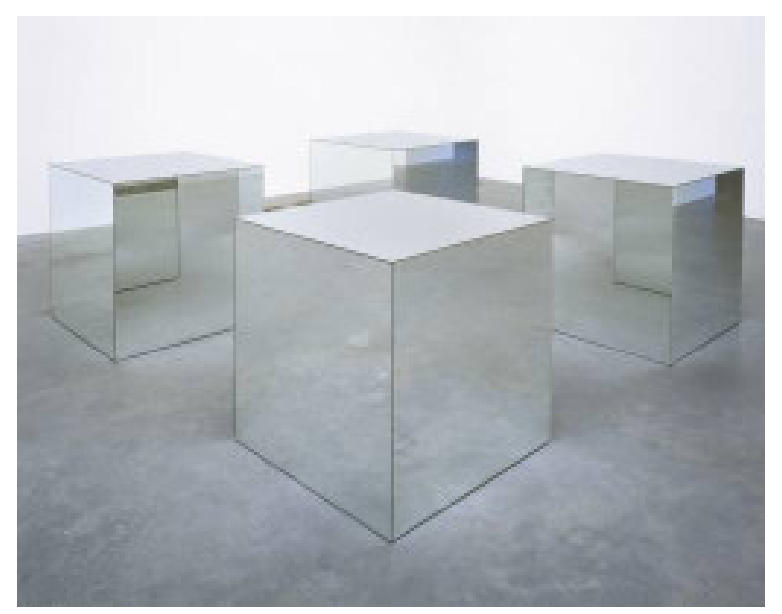

Figura 3: Untitled, Robert Morris, Tate Modern, 1965-71. Fonte: http://www.tate.org.uk/collection/T/T01/ T01532_9.jpg.

Finalmente o artista Richard Serra, que com suas imensuráveis formas ambientais como o trabalho eight torqued ellipses e snake (figura 4) transforma o entorno produzindo um novo ambiente, irremediavelmente transformado. Uma obra "site-specific" é criada para existir no espaço, que por sua vez ganha dimensão e constitui-se na ação exploratória dos visitantes.

Como afirma Noë (2000, p.132) "uma experiência perceptiva como um modo de exploração ativa do mundo". Antes de qualquer movimentação das pessoas em torno, este trabalho só existe na sua gigantesca proporção, mas que gradativamente ganha compreensão e estabelece relações com o espaço na medida em que os deslocamentos dos leitores revelam e desnudam sua dimensão física.

A leitura não se dá por inteiro, em momento algum, mas a sua existência no tempo permite a reconstituição do todo enquanto fruímos partes.

A seguir:

Figura 4: Eight torqued ellipses - snake, Richard Serra, 1996-99.Fonte: http:// www.spliteye.com/ serra/ 


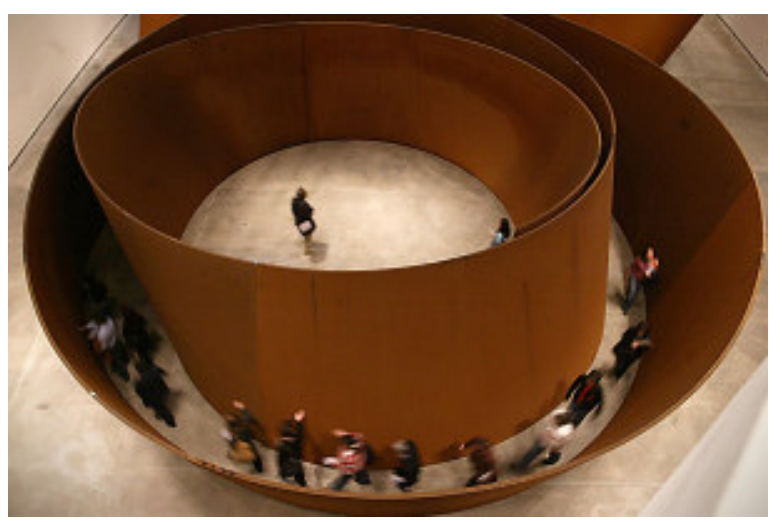

Refletir sobre os padrões de percepção e ação - modos de aproximação e distanciamento, significa pensar sobre uma forma de corpo comprometida com a situação, que como diz Borges (2006, p.31) "é um espaço significativo, um espaço como propriedade de acontecimentos" onde "as tensões musculares estão no corpo mas também no espaço. Os corpos se cruzam; o espaço é cheio". Um corpo sempre na postura de relação - um corpo que caminha entre outros corpos e objetos, e que se ajusta aos mesmos pela dinâmica das tensões musculares que são operações de posição, postura, atitude, direção (Gaiarsa, 1988, p.66). O corpo ao movimentar-se implica na elaboração de configurações específicas de forças, que por sua vez implicam em maneiras próprias de apreciar, de agir e de reagir. Na articulação destas tensões o corpo existe e se reconhece no espaço.

Articular a fenomenologia para refletir sobre estas interfaces "enactive" implica em assumir o conceito de experiência como uma atividade de encontro com o mundo, determinada por contingências sensório-motoras. A relação com o mundo acontece dependente do estímulo sensório e dos movimentos em torno; por exemplo, um tomate é reconhecido pelas partes visíveis, enquanto a compreensão das não-visíveis pode depender de uma reorientação do leitor em torno do objeto e não somente de construções mentais. Vale reforçar que o conteúdo apresenta-se a partir de experiências perceptivas, atividades baseadas na exploração do ambiente, onde o conhecimento não se dá como um todo, mas "enacted", estendido no tempo das ações. Em contraste, por exemplo, a relação com a torre Eiffel não está agora momentaneamente mediada pelas contingências sensório-motoras, mas dependente de um processo cognitivo de inferências sobre o objeto mediado por outros suportes ou mesmo até experienciado anteriormente. (Noë, 2002) Admite-se assim que a estrutura fisiológica do corpo e suas experiências sensórias com o ambiente, tanto quanto os processos neurais, assumem um papel determinante no desenvolvimento dos artefatos tecnológicos, cada vez mais estruturados, segundo nos parece, a partir deste conhecimento "enactive" para evocar a interação usuário/interface.

A ênfase nas qualidades da ação mais do que no conhecimento da representação, assegura interfaces onde a aprendizagem dá-se com o ato do fazer. Como conseqüência direta o desenvolvimento de interfaces tecnológicas tem procurado por características morfológicas e funcionais cada vez mais compatíveis com as estruturas humanas e numa dependência direta da experiência incorporada nas ações do cotidiano. As empresas de bens de consumo tecnológicos vêm assim investindo de forma clara e objetiva em acessórios que apresentam um alto grau de inserção na relação diária dos indivíduos com o mundo; diante desta demanda, cada vez mais os objetos/aparelhos demonstram a existência de estudos cognitivos para construir a relação usuário/interface e recuperar em parte o conhecimento corpóreo já culturalmente interiorizado.

Como exemplo, pontua-se o desenvolvimento da interface i-phone da Macintosh, no qual a escolha de um determinada tarefa entre os ícones na interface gráfica acontece por um pequeno movimento, já conhecido - o afastar e aproximar dos dedos polegar e indicador. Outro movimento, já incorporado, que leva o dedo indicador para direita ou para esquerda enquanto percorre os ícones de funções também recupera em parte a idéia de interesse e/ou desinteresse por algo.

Outro exemplo, também recente, é o videogame Wii da Nintendo que vem revolucionando o mundo do entretenimento diante do peculiar modo de jogar: um controle que captura os movimentos do jogador, braços, tronco, pernas, para acionar funções e controlar as ações dos avatares nos jogos. $\mathrm{O}$ dispositivo possui sensores de movimento, ângulo e força, que recuperam de forma óbvia toda a movimentação corpórea, gestos e deslocamentos, já apreendidos em outras situações vividas pelos participantes. As funções, comportamentos e gestualidades, não são pré-dadas mas sim resgatadas de referências em ações outras, contextualmente determinadas e significadas pelo senso comum. Assim, jogar tênis com o Wii implica necessariamente em pular, girar, abaixar-se, levantar-se, com a intenção objetiva de bater na bolinha e resgatar qualquer experiência já vivenciada em uma quadra de tênis.

Assim, a experiência de existir e de gerar significados acontecem de forma inseparável e trazem, como afirma Merleau-Ponty (apud Dourish, 2004, p.114) a relação sujeito/objeto focada em uma "teoria do corpo e conseqüentemente uma teoria da percepção". Partindo-se desta premissa fenomenológica, pode-se pensar sobre a relação usuário/interface dependente de uma íntima relação entre percepção e ação (modos de apreensão), sendo que o indivíduo e o ambiente nas suas condições corporais e matéricas, respectivamente, estão implicitamente considerados na determinação destas interfaces tecnológicas. Em consonância com estas premissas cita-se Armstrong (apud Bennet e O'Modhrain, 2007, p.38) e o critério de "interação incorporada" que descreve como "uma atividade incorporada de maneira a ser situada, em tempo real, multimodal, engajada, e com o sentido de 
incorporação como um fenômeno emergente". Na medida em que a interface e seu funcionamento dependem diretamente das ações dos usuários, fica claro a noção de engajamento dos mesmos e não apenas considerações sobre os seus níveis de atenção; nesta condição a sincronização temporal das interações vem reforçar que o estado do sistema computacional altera-se dinâmica e diretamente relacionado com as trocas realizadas.

\section{Experimentações artísticas}

No processo contínuo e imbricado entre objetos e espaço, este deixa de ser representação, e assume-se enquanto processo de construção, e como afirma Ferrara (2007, p.12) um lugar fenomênico a ser preenchido pelas ações no qual se reconhece "a emergência do espaço como experiência sensível". O espaço passa a ser explorado, construído, habitado, enquanto movimentos de mediação, interação, percepção, entre sujeitos - corpos, objetos e questões sociais. Ao falar desta forma, justifica-se apresentar algumas pesquisas e produções em arte e tecnologia, que se configuram como um local recorrente desta experimentação. As obras procuram, claramente, não afirmar a produção e os recorrentes usos da sociedade tecnológica, mas gerar como afirma Machado (2004, p.6) "instrumentos críticos para pensar o modo como as sociedades contemporâneas constituem-se, reproduzemse e se mantêm".

\subsection{Fugitive 2}

Fugitive 2 instiga o participante a perseguir imagens, que se afastam na medida em que a aproximação do mesmo coincide com a distância limite enquanto gera a percepção de movimento de zoom in da câmera no vídeo. O artista Simon Penny tem como objetivo principal na obra discernir aspectos sutis do comportamento das pessoas ao capturar a dinâmica temporal dos movimentos de ir e vir dos mesmos.

O importante é considerar a aceleração e velocidade dos deslocamentos no interior do espaço, uma situação do corpo em relação, rastreados por sensores e acelerômetros, mais do que a posição instantânea no próprio ambiente.

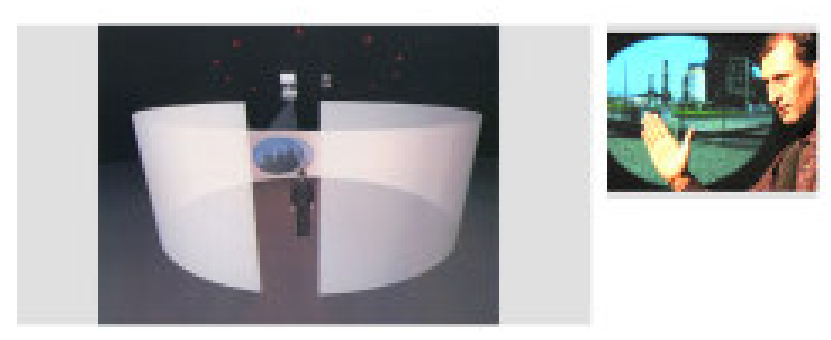

Figura 5: Fugitive 2, Simon Penny, 2004.

Fonte: http://ace.uci.edu/penny/works/fugitive2.html.

\subsection{Cylindres}

O artista Pierre-Guillaume Clos explora esteticamente um fenômeno cotidiano, mas que nem sempre é avaliado pelas pessoas: a nossa percepção do espaço depende diretamente da posição e inter-relação dos objetos no mesmo. Esta experiência estética questiona o que acontece com a compreensão do espaço físico quando os objetos movem-se; a percepção do entorno sofre transformações nas suas dimensões básicas de largura, comprimento e profundidade, que passam a formalizar-se dinâmica e empiricamente.

Na instalação, três cilindros (figura 6) rolam paralelos e independentemente sem que qualquer causa física produza tais deslocamentos. Estes deslocamentos dos cilindros foram criados através de uma simulação gerada no software Mimesis e passam a ser controlados. Assim, os visitantes ali presentes constroem a percepção sensória do espaço a partir das relações com os cilindros e destes com o espaço, que se revela maior ou menor conforme a distribuição e localização dos mesmos.

Os visitantes da exposição, "Enaction in Arts", Grenoble, Novembro de 2007, na medida em que precisam contornar, parar e pular os cilindros para evitar um choque, encontram-se em um processo dinâmico de construção e entendimento do espaço ocupado; este conhecimento acontece a cada momento que os participantes atualizam uma referência espacial dependente da relação corpo/objeto.

Outros limites espaciais são determinados não mais dependentes de uma leitura inicial dada pelo participante, mas em consonância com as exigências pontuais, constantes readaptações para o equilíbrio biomecânico do corpo em movimento foram evocadas, aí sim, dependentes da capacidade de auto-organização. Assim, para cada disposição dos cilindros no espaço, os participantes reordenam-se, assumindo distintas posições e portanto reocupando-o; uma tentativa quase espontânea de dialogar com os objetos, promovendo um estado de equilíbrio ou de tensão e qualificando a própria existência no contexto físico.

A seguir:

Figura 6: Três cilindros paralelos dispostos no chão do espaço expositivo. Fonte: Luisa Paraguai. No vembro de 2007. 


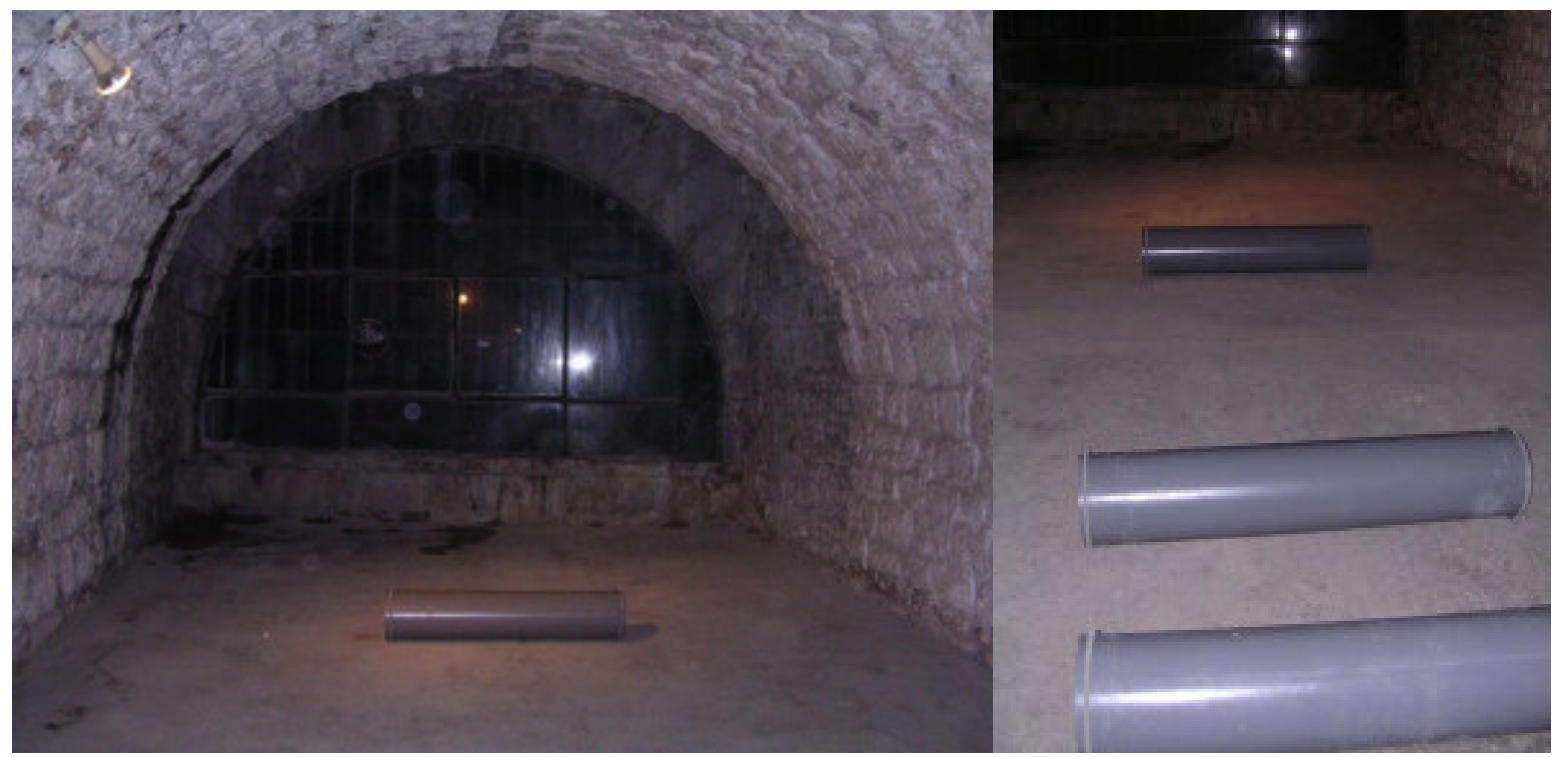

\subsection{Seven mile boots}

Neste projeto, "seven mile boots" a artista Laura Beloff e seus colaboradores Erich Berger e Martin Pichlmair criaram um par de botas que permite incursões físicas através de espaços virtuais. Foram apresentadas no ISEA 2004 em Tallinn, Estônia, e no Ars Electronica 2004, em Linz, Áustria. Valendo-se da lenda folclórica, onde um par de botas era capaz de fazer a pessoa andar sete mil léguas em um passo, os artistas desenvolveram um par de botas vermelhas (figura 7) permitindo o usuário enquanto anda fisicamente percorrer "distâncias" na Internet, navegando e escutando/observando as salas de bate-papo. Alguns teóricos vêm nomeando esta condição como híbrida, quando "atuar" significa coexistir em contextos distantes e atuais simultaneamente, na medida em que os limites entre espaços virtuais e físicos esvanecem-se. O usuário continua presente/atuante no seu espaço físico em torno enquanto as informações recebidas e transmitidas remotamente adicionam outras características a esta experiência fenomenológica. Para de Souza e Silva (2006, p.26) um espaço híbrido apresenta-se como um local de comunicação, "caracterizado por três perspectivas descritas como espaços conectados, espaços móveis e espaços sociais".

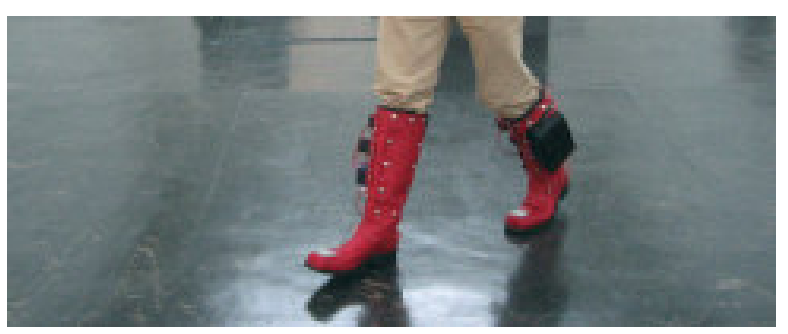

Figura 7: Seven mile boots, Laura Beloff, 2003-4. Fonte: http:/ / randomseed.org/sevenmileboots/

\section{Considerações finais}

O fato de atuar no mundo implica na construção da realidade do espaço, um contexto que se reconhece a partir da dinâmica dos movimentos e gestos corpóreos comportamentos, que redefinem constantemente as relações espaciais. O conceito de "espaço incorporado" de Low (2003, p.9) apresenta um modelo de compreensão para a criação do espaço através da "orientação espacial, movimento e linguagem" das pessoas, e cabe aqui neste trabalho perfeitamente para contextualizar as interferências sugeridas pelos dispositivos na relação participante/corpo/espaço.

A percepção do espaço é reconhecidamente dinâmica e fluída, diretamente relacionada com a ação, isto é, com o que pode ser feito em um determinado contexto. Segundo de Kerckhove (1997, p.24): “(...) Instalações Artísticas Interativas fazem o papel de conectores diante do fazer não mais preocupado em gerar objetos, mas produzir contextos. Eles convidam os usuários a interiorizar o que eles estão experienciando, fazer novas conexões, em outras palavras, remapear nossos sistema nervoso." Os trabalhos fugitive 2 e cylindres apresentam esta condição onde indivíduo e objeto, determinam-se um na existência possível do outro, isto é, constroem significância na medida em que as relações participante/imagem e participante/cilindros, respectivamente, acontecem diferentemente no tempo. O trabalho seven mile boots qualifica poeticamente e habilita a condição de coexistir simultaneamente no ciberespaço sonoro dos chats enquanto o usuário circula no ambiente físico. Estes trabalhos operam assim com as características emergentes de um conhecimento que depende do "estar no mundo" integrando corpos, percepção e consciência. Como afirma Varela (2000, p.149-150):

O mundo não é dado a priori, independente do referente, mas seu conhecimento é um processo ativo, de recuperação e construção constantes por par- 
te dos indivíduos reconhecidamente aculturados. Em outras palavras, apesar da capacidade de compreensão do mundo ser baseada nas estruturas biológicas de cada indivíduo, é experienciada e vivida no domínio da ação consensual e da história cultural. Portanto, não considerar as relações históricas sociais, econômicas, políticas, envolvidas na leitura destes indivíduos implica em negar territórios, limites tecnológicos, categorias do social, classes de poder mamecos

\section{NOTAS}

* Este texto foi apresentado no II Simpósio Nacional da ABCiber realizado em novembro de 2008.

\section{REFERÊNCIAS}

BENNET, P.; O'MODHRAIN, S. Towards Tangible Enactive-Interfaces. In Proceedings of the $4^{\text {th }}$ International Conference on Enactive Interfaces. p.37-40. Grenoble, France: Association ACROE, 2007.

BORGES, F.C. A filosofia do jeito, um modo brasileiro de pensar com o corpo. São Paulo, Summus Editorial, 2006.

De KERCKHOVE, D. Connected intelligence, the arrival of the Web society. Toronto: Sommerville House Publishing, 1997.

DeSOUZA ESILVA, A.A. Do ciber ao híbrido: tecnologias móveis como interfaces de espaços híbridos. In: ARAÚJO, Denize Correa (org). Imagem (ir)realidade, comunicação e cibermídia. Porto Alegre: Sulina, p.2151, 2006.

DOURISH, P. Where the action is: the foundations of embodied interaction. Cambridge: The MIT Press, 2004.

FERRARA, L. D'A. (org.) Espaços Comunicantes. São Paulo: Annablume; Grupo ESPACC, 2007.

FITZMAURICE, G.W. Graspable User Interfaces. Thesis. Toronto, Canada: Department of Computer Science, University of Toronto, 1996. Disponível em: <http:// www.dgp.toronto.edu/ gf/papers/PhD\%20\%20Graspable\%20UIs/Thesis.gf.html\#RTFToC6>. Acesso em: $<20$.outubro.2008>.

GAIARSA, J.A. A estátua e a bailarina. São Paulo: Ícone, 1988.

LOW, S.M. Anthropological theories of body, space, and culture. In: Space and Culture, vol.6, n.1, pp.9-18, 2003.

McGANN, M. What is enactive cognition. Disponível em: <http:/ / www.eucognition.org/wiki/ index.php?title=What_is_\%22Enactive\%22_Cognition\%3F $>$. Acesso em: $<16$. setembro.2008>.
MACHADO, A. Arte e Mídia: aproximações e distinções. E-compos, edição 1, p.1-15, dezembro, 2004. Disponível em: <http://www.compos.org.br/e-compos>. Acesso em: 16.maio.2006.

NOË, A. Art as enaction. In: Art and Cognition Conference. Novembro, 2002. Disponível em: < http:// www.interdisciplines.org/artcog/papers/8>. Acesso em: $<20$.outubro.2008>.

NOË, A. Experience an Experiment in Art. In: Journal of Consciousness Studies, vol.7, n.8-9, pp.123-135, 2000.

PASQUINELLI, E. Enactive Knowledge. In: LUCIANI, A.; CADOZ, C. (ed). Enaction and enactive interfaces, a handbook of terms. p.93. Grenoble: Enactive Systems Books, 2007.

SANTOS, M. A natureza do espaço: Técnica e Tempo. In: Razão e Emoção. 3a Edição. São Paulo: Hucitec, 1999.

STEWART, J. Enactive Cognitive Science_1. In: LUCIANI, A.; CADOZ, C. (ed). Enaction and enactive interfaces, a handbook of terms. p.89-91. Grenoble: Enactive Systems Books, 2007.

ULLMER, B.; ISHII, H. Emerging frameworks for tangible user interfaces. In: IBM Systems Journal, vol.39, n. $3 \& 4,2000$.

VARELA, F.J. Las ciencias cognitivas: tendencias y perspectivas. In: Cartografía de las ideas actuales. $2^{\mathrm{a}}$ reimpresión. Barcelona: Editorial Gedisa, 1998.

VARELA, F.J;; THOMPSON, E.; ROSCH, E. The embodied mind, cognitive science and human experience. $8^{a}$ edição. Cambridge, London: The MIT Press, 2000. 